\title{
Dual role of the p38 MAPK/cPLA 2 pathway in the regulation of platelet apoptosis induced by ABT-737 and strong platelet agonists
}

\author{
N Rukoyatkina ${ }^{1,2}$, I Mindukshev ${ }^{2}$, U Walter ${ }^{3}$ and S Gambaryan ${ }^{\star, 1,2}$
}

p38 Mitogen-activated protein (MAP) kinase is involved in the apoptosis of nucleated cells. Although platelets are anucleated cells, apoptotic proteins have been shown to regulate platelet lifespan. However, the involvement of p38 MAP kinase in platelet apoptosis is not yet clearly defined. Therefore, we investigated the role of p38 MAP kinase in apoptosis induced by a mimetic of BH3-only proteins, ABT-737, and in apoptosis-like events induced by such strong platelet agonists as thrombin in combination with convulxin (Thr/Cvx), both of which result in p38 MAP kinase phosphorylation and activation. A p38 inhibitor (SB202190) inhibited the apoptotic events induced by ABT-737 but did not influence those induced by Thr/Cvx. The inhibitor also reduced the phosphorylation of cytosolic phospholipase $A_{2}$ (cPLA2), an established p38 substrate, induced by ABT-737 or Thr/Cvx. ABT-737, but not Thr/Cvx, induced the caspase 3-dependent cleavage and inactivation of cPLA2. Thus, p38 MAPK promotes ABT-737induced apoptosis by inhibiting the CPLA2/arachidonate pathway. We also show that arachidonic acid (AA) itself and in combination with Thr/Cvx or ABT-737 at low concentrations prevented apoptotic events, whereas at high concentrations it enhanced such events. Our data support the hypothesis that the p38 MAPK-triggered arachidonate pathway serves as a defense mechanism against apoptosis under physiological conditions.

Cell Death and Disease (2013) 4, e931; doi:10.1038/cddis.2013.459; published online 21 November 2013

Subject Category: Experimental Medicine

Platelets play a key role in normal and pathological hemostasis through their ability to rapidly adhere to activated or injured endothelium and subendothelial matrix proteins (platelet adhesion), and to other activated platelets (platelet aggregation). ${ }^{1}$ Platelets are also considered as key mediators of thrombosis, vascular inflammation, and atherosclerosis. ${ }^{2,3}$

Apoptosis play a significant role in platelet production from megakaryocytes, and circulating platelets contain many components of the apoptotic machinery. ${ }^{4}$ Indeed, cytochrome c, caspase 9, caspase 3, apoptotic protease-activating factor, and $\mathrm{Bcl}-2$ family proteins (for example, BAK, BAX, Bcl- $\mathrm{X}_{\mathrm{L}}, \mathrm{Bcl}-$ $\left.2, \mathrm{BCl}_{\mathrm{w}}, \mathrm{Bim}, \mathrm{Bid}\right)$ are all expressed in platelets. ${ }^{5-8}$

A variety of stimuli can induce apoptotic or apoptotic-like events in platelets, such as ABT-737, thrombin, collagen, and $\mathrm{A} 23187 . \mathrm{ABT}-737$, a potent mimetic of $\mathrm{Bcl}-2$ homology $\mathrm{BH}-$ only proteins (including Bim, Bid, and other proteins that can be important for binding and neutralizing antiapoptotic $\mathrm{Bcl}-2$ family proteins), induces caspase-dependent platelet apoptosis that is associated with BAX translocation from the cytosol to mitochondria and homo-oligomerization. ${ }^{7}$ In highly activated platelets, several structural and functional changes, such as phosphatidylserine (PS) externalization, cell shrinkage, loss of mitochondrial membrane potential $\left(\Delta \Psi_{\mathrm{m}}\right)$, microparticle (MP) formation, and cleavage of gelsolin and protein kinase $\mathrm{C}-\delta$, are reminiscent of nucleated cell apoptosis. ${ }^{9-13}$ However, strong agonists either did not activate caspase $3^{14}$ or did so very weakly. ${ }^{15-17} \mathrm{~A}$ total of 13 types of cell death have been characterized for nucleated cells, including caspase-dependent and caspaseindependent intrinsic apoptosis, autophagic cell death, necroptosis and others. ${ }^{18}$ Although highly activated platelets exhibit the characteristic features of dying cells, there is no consensus in the literature clearly defining the type of strong activated platelet death. Some authors define them as necrotic cells ${ }^{19}$ whereas others ${ }^{11,20,21}$ consider them as apoptotic platelets.

Mitogen-activated protein (MAP) kinases represent a family of threonine/tyrosine-activated serine/threonine kinases that control many cellular responses, such as proliferation, migration, differentiation, and apoptosis. In platelets, p38 MAP kinase is phosphorylated and activated by different physiological agonists, including thrombin, collagen, and thromboxane $A_{2}\left(T x A_{2}\right){ }^{22-25}$ However, the mechanisms of p38 activation and their downstream effects are controversial and have not been clearly defined. p38 has been suggested to regulate platelet adhesion to collagen ${ }^{26}$ and aggregation. ${ }^{24,27}$ In contrast, using different p38 inhibitors, other authors did not find any significant effect of p38 on platelet activation. ${ }^{28-31}$

\footnotetext{
${ }^{1}$ Institute of Clinical Biochemistry and Pathobiochemistry, University of Würzburg, Würzburg D-97080, Germany; ${ }^{2}$ Sechenov Institute of Evolutionary Physiology and Biochemistry, Russian Academy of Sciences, St Petersburg 194223, Russia and ${ }^{3}$ Center for Thrombosis and Hemostasis (CTH), Johannes Gutenberg University, Mainz 55131, Germany

*Corresponding author: S Gambaryan, Institute of Clinical Biochemistry and Pathobiochemistry, University of Würzburg, Grombühlstr. 12, Würzburg D-97080, Germany. Tel: +49 93132 93617; Fax: +49 93132 93630; E-mail: gambaryan @klin-biochem.uni-wuerzburg.de

Keywords: platelet; apoptosis; p38 MAP kinase; $\mathrm{CPLA}_{2}$

Abbreviations: $A A$, arachidonic acid; $\mathrm{CPLA}$, cytosolic phospholipase $\mathrm{A}_{2} ; \Delta \Psi_{\mathrm{m}}$, mitochondrial membrane potential; MP, microparticle; ROS, reactive oxygen species; $\mathrm{Thr} / \mathrm{Cvx}$, thrombin/convulxin; $\mathrm{TxA}_{2}$, thromboxane $\mathrm{A}_{2} ; \mathrm{WP}$, washed platelets

Received 16.9.13; revised 21.9.13; accepted 22.10.13; Edited by A Stephanou
} 
One of the established p38 substrates in platelets is cytosolic phospholipase $A_{2}\left(C P L A_{2}\right)$, which is phosphorylated by p38 at serine505 in agonist-stimulated platelets. ${ }^{32-34}$ In platelets, $\mathrm{CPLA}_{2}$ activity is responsible for the release of arachidonic acid (AA) from membrane phospholipids. ${ }^{35} \mathrm{AA}$ is then metabolized by cyclooxygenase to prostaglandins, which are further converted to $\mathrm{TxA}_{2}$ by thromboxane synthase (TxS). In addition, AA is involved in the regulation of reactive oxygen species (ROS) production. $\mathrm{CPLA}_{2}$-induced $A A$ is a prominent requirement for the activation of NADPH oxidase and generation of ROS in phagocytes. ${ }^{36}$ ROS may also be generated as a by-product during the oxidation of $\mathrm{AA}$ by cyclooxygenase or lipoxygenase. ${ }^{37,38}$ Therefore, platelet $\mathrm{CPLA}_{2}$ is involved in the regulation of two different functions, ROS generation and eicosanoid production. Excess ROS generation and $A A$ release play essential roles in the initiation of apoptosis in platelets. ${ }^{21,39} \mathrm{As} \mathrm{p38/cPLA}$ is involved in the regulation of nucleated cell apoptosis ${ }^{40-43}$ and the possible involvement of $\mathrm{p} 38 / \mathrm{cPLA} \mathrm{A}_{2}$ in the induction of platelet apoptotic events is not known, we compared the mechanism of $\mathrm{p} 38$ / $\mathrm{CPLA}_{2}$-mediated signaling induced by platelet agonists and ABT-737.

In this study, we show that p38 plays a significant role in ABT-737-induced platelet apoptosis, whereas it has no effect on thrombin in combination with convulxin(Thr/Cvx)-induced apoptotic-like events. ABT-737, but not Thr/Cvx, induced the caspase-dependent cleavage and inactivation of $\mathrm{CPLA}_{2}$. We also assessed multiple influences of AA/ROS on apoptotic-like events in platelets and suggest that the p38triggered arachidonate pathway serves as a defense mechanism under physiological conditions.

\section{Results}

Activation of p38 MAP kinase plays a significant role in ABT-737-induced platelet apoptosis. To clarify the function of p38 in platelet apoptosis induced by two independent pathways, the $\mathrm{BH} 3$ mimetic compound $\mathrm{ABT}-737$ was used as an activator of the BAK/BAX-caspase pathway and a combination of Thr/Cvx as agonists of the second caspaseindependent pathway.

In our study, we used terms apoptosis-like events for platelets activated by strong agonists and apoptosis for ABT737-induced platelet death. ABT-737 at concentrations ranging from 0.1 to $1 \mu \mathrm{M}$ induced dose- and time-dependent increases in Annexin V binding (Figures 1a and c). Simultaneously, ABT-737 $(0.1-1 \mu \mathrm{M})$ time dependently increased the phosphorylation of p38 (Figure 1b). In contrast to Thr/Cvx, ABT-737 did not activate $\alpha \mathrm{llb} \beta 3$ integrins (Figure 1c) and did not induce MP formation (Figures $6 a$ and $b$ ). The activation of p38 by thrombin and convulxin alone or in combination (Thr/ Cvx) was transient, reaching a maximum after $5 \mathrm{~min}$ of incubation and then gradually decreasing to a level comparable with that of the control after $60 \mathrm{~min}$ (Figure 1d). Conversely, activation of p38 by ABT-373 was detectable only after $20 \mathrm{~min}$ of stimulation and remained constant even up to $90 \mathrm{~min}$ of stimulation (Figure 1a). A p38 inhibitor (SB202190, $1 \mu \mathrm{M})$ significantly decreased the amount of Annexin V-positive platelets $(67 \pm 3 \%$ compared with a

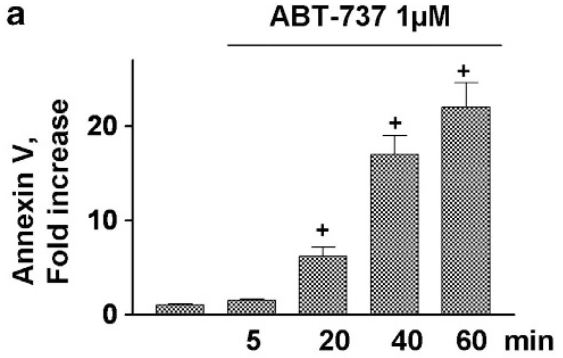

b

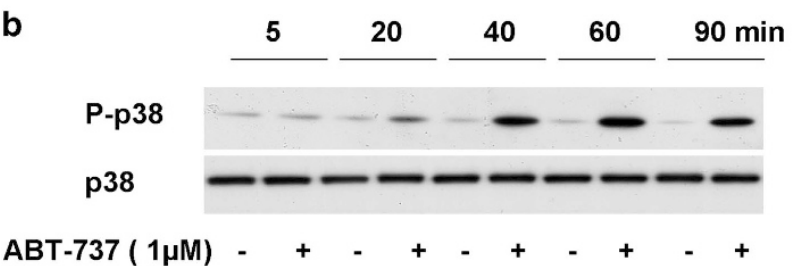

c

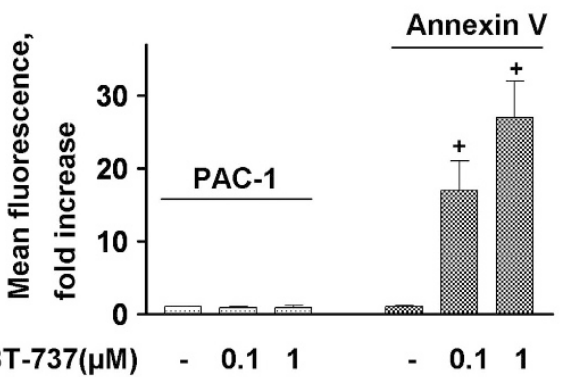

d

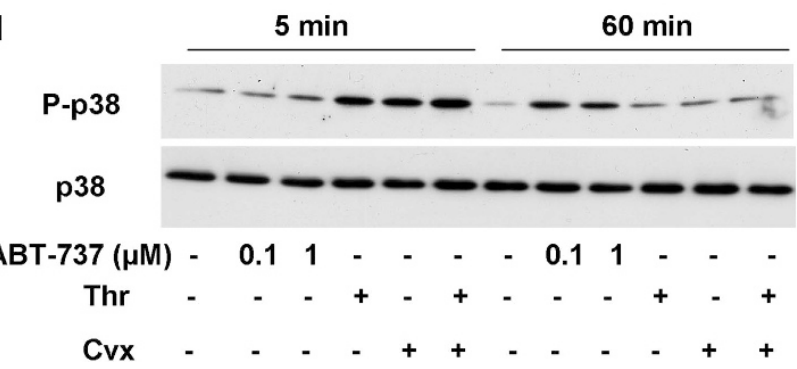

Figure $1 \mathrm{BH} 3$ mimetic (ABT-737) phosphorylates p38. (a) FACS analysis of Annexin $\mathrm{V}$ binding and (c) PAC-1 binding (integrin $\alpha$ llb $\beta 3$ activation, mean fluorescence, $A U)$ to WP $\left(1 \times 10^{7} / \mathrm{ml}\right)$ incubated with $A B T-737$. Annexin $V$ and PAC-1 binding are presented as the fold increase compared with the control taken as 1. Data are presented as means \pm S.E.M, $n=5 ;+P<0.05$ compared with the control. (b and d) Western blot analysis using WP $\left(4 \times 10^{8} / \mathrm{ml}\right)$ of p38 phosphorylation after incubation with thrombin $(5 \mathrm{mU} / \mathrm{ml})$ and convulxin $(5 \mathrm{ng} / \mathrm{ml})$ or ABT-737 $(0.1-1 \mu \mathrm{M})$ (data shown are representative of three independent experiments)

ABT-737-stimulated platelets taken as 100\%) and prevented decreases in $\Delta \Psi_{m}(32 \pm 4 \%)$ stimulated by ABT-737 (Figures $2 a$ and b). Similarly, SB202190 inhibited the cleavage of procaspase 3 by $31 \pm 3 \%$ (Figures $2 \mathrm{c}$ and d), indicating that p38 is partly involved in ABT-737-induced caspase 3 activation and apoptosis.

p38 MAP kinase is not involved in the generation of apoptotic-like events triggered by Thr/Cvx. We next investigated whether the activation of p38 is involved in Thr/Cvx-induced platelet death. The activation of platelets by Thr/Cvx significantly increased Annexin V binding 7.6 \pm 1.5 

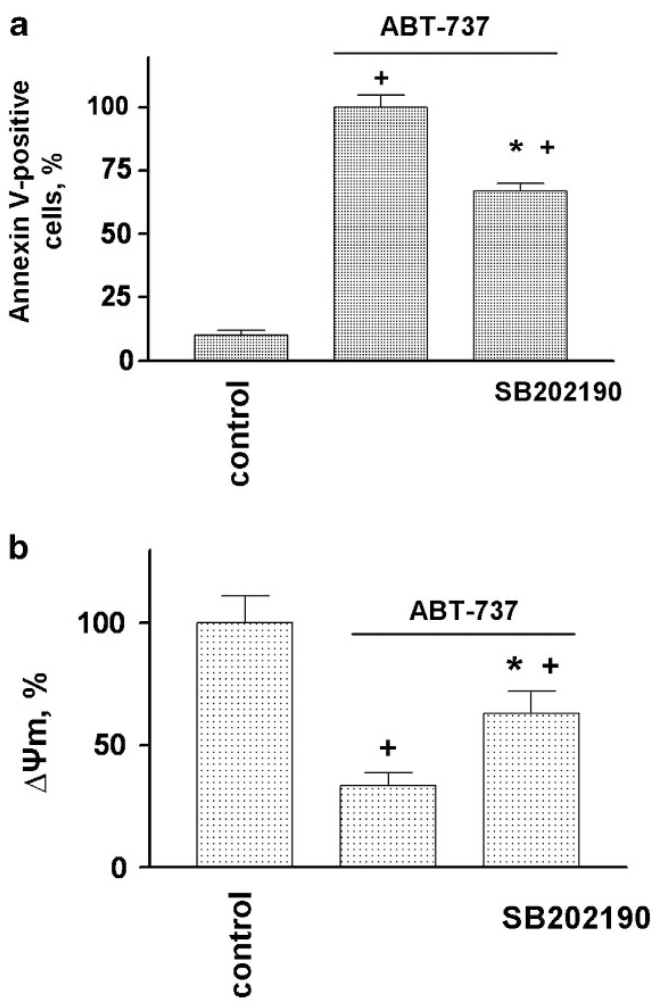

C
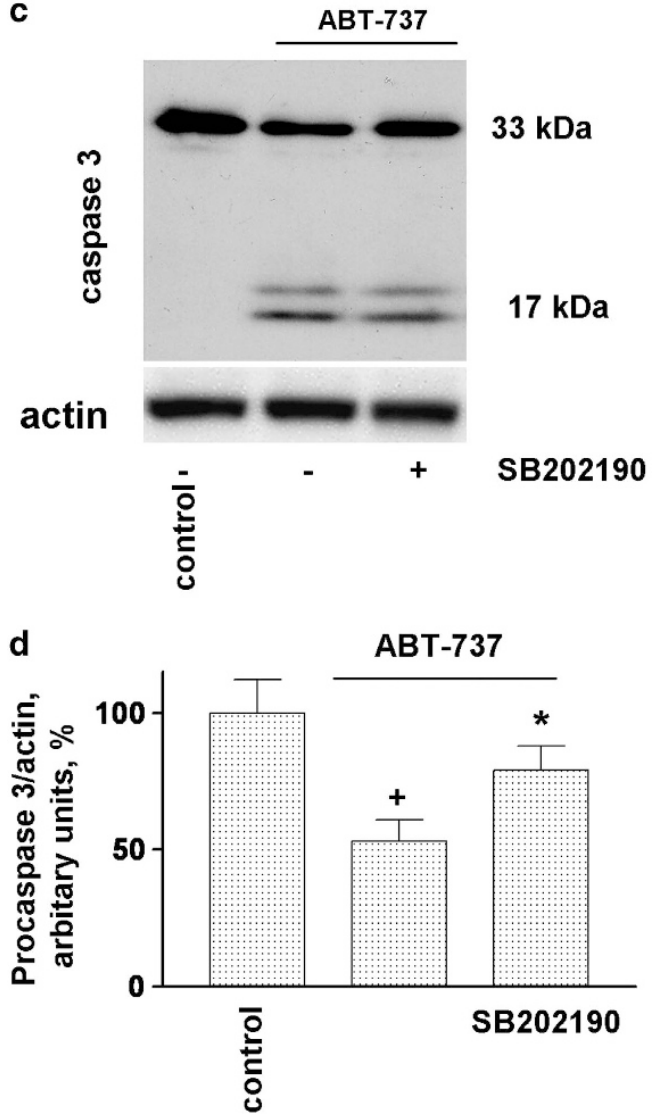

compared with control $1 \pm 0.14$ ) and $\alpha \mathrm{llb} \beta 3$ integrin activation (Figure 3a). The inhibition of p38 (SB202190, $1 \mu \mathrm{M})$, as assessed by the phosphorylation of its established substrate (HSP27) (Figures $3 c$ and d), did not significantly inhibit Annexin $V$ binding (Figure $3 a$ ) or decreases in $\Delta \Psi_{\mathrm{m}}$ (Figure $3 b$ ) and had no effect on $\alpha \mathrm{llb} \beta 3$ integrin activation (Figure 3a), indicating that p38 is not involved in Thr/Cvxinduced platelet apoptotic-like events.

Platelet $\mathrm{CPLA}$, cleavage by $\mathrm{ABT}-737$ is caspase dependent. The stimulation of platelets by Cvx and Thr/Cvx (both $5 \mathrm{~min}$ ) and by $\mathrm{ABT}-737$ (30 min) induced p38 and $\mathrm{CPLA}_{2}$ phosphorylation, and the latter was partly (in the case of Cvx and Thr/Cvx) and fully (in the case of ABT-737) prevented by preincubation with SB202190 (Figures 4a and b). However, in contrast to Cvx and Thr/Cvx, ABT-737 induced the cleavage of $\mathrm{cPLA}$, which was prevented by a procaspase 3 inhibitor (z-DEVD-fmk) at concentrations of $50-100 \mu \mathrm{M}$ (Figures $4 \mathrm{c}$ and $\mathrm{d}$ ). We then tested whether the cleavage of $\mathrm{CPLA}_{2}$ would inhibit its activity. One of the main functions of $\mathrm{CPLA}_{2}$ in platelets is associated with the production of thromboxane $\left(\mathrm{TxA}_{2}\right)$ TxS. ABT-737 $(1 \mu \mathrm{M})$ induced only a weak activation of TxS ( $4 \pm 0.3$-fold increase compared with the control taken as 1), Cvx and Thr/Cvx (Figure 4e) strongly activated TxS ( $20 \pm 1.3$ - and $52 \pm 1.3$-fold, respectively). The inhibition of p38 (SB202190, $1 \mu \mathrm{M})$ decreased the TxS activity induced by Cvx or Thr/Cvx to $75 \pm 1.7 \%$ and $87 \pm 1.8 \%$, respectively, compared with the agonist-induced activity taken as $100 \%$ (Figure $4 \mathrm{f}$ ).

Arachidonic acid prevents apoptosis in platelets at low concentrations and induces apoptosis in platelets at high concentrations. In nucleated cells, AA has been shown to contribute to mitochondrial dysfunction during apoptosis; ${ }^{44,45}$ however, AA was used at very high concentrations (more than $10 \mu \mathrm{M}$ ) in these studies. The depletion of AA prevents apoptotic development in cold-stored platelets whereas incubation with extremely high concentrations of $A A$ $(50-100 \mu \mathrm{M})$ induces platelet apoptosis. ${ }^{39}$ In the present study, we tested whether AA would contribute to apoptosis in freshly isolated platelets. Washed platelets (WP) were incubated with different concentrations of $\mathrm{AA}\left(10^{-7}\right.$ to $\left.10^{-4} \mathrm{M}\right)$, and apoptosis was assessed by decreases in $\Delta \Psi_{\mathrm{m}}$, PS exposure, and procaspase 3 cleavage. At high concentrations $\left(10^{-5}\right.$ and $\left.10^{-4} \mathrm{M}\right)$, AA did indeed induce a decline in $\Delta \Psi_{\mathrm{m}}$ (Figure $5 \mathrm{a}$ ) and an increase in Annexin $\mathrm{V}$ binding (Figure $5 \mathrm{~b}$ ) and cleavage of procaspase 3 after $24 \mathrm{~h}$ of incubation (Figure $5 \mathrm{c}$ ). However, at low concentrations $\left(10^{-6}\right.$ and $\left.10^{-7} \mathrm{M}\right), \mathrm{AA}$ appeared to have antiapoptotic effects: it did not affect Annexin $\mathrm{V}$ binding, slightly increased

Figure 2 p38 MAP kinase inhibition prevents ABT-737-induced platelet apoptosis (a) FACS analysis of Annexin V-positive platelets $\left(1 \times 10^{7} / \mathrm{ml}\right)$ and (b) mitochondrial membrane potential $\left(\Delta \Psi_{m}\right)$ in WP incubated with ABT-737 $(0.1 \mu \mathrm{M}, 30 \mathrm{~min})$ or pretreated $(10 \mathrm{~min}, 1 \mu \mathrm{M})$ with p38 inhibitor (SB202190). (c) Western blot and (d) densitometry analyses of caspase 3 in human WP $\left(4 \times 10^{8} / \mathrm{ml}\right)$ incubated with ABT-737 $(0.1 \mu \mathrm{M})$ or pretreated $(10 \mathrm{~min}, 1 \mu \mathrm{M})$ with p38 inhibitor (SB202190). In (a), ABT-737 was taken as 100\%; in (b) and (d), the control was taken as $100 \%$. Data are presented as means \pm S.E.M, $n=4 ;+P<0.05$ compared with the control, ${ }^{*} P<0.05$ compared with ABT-737 


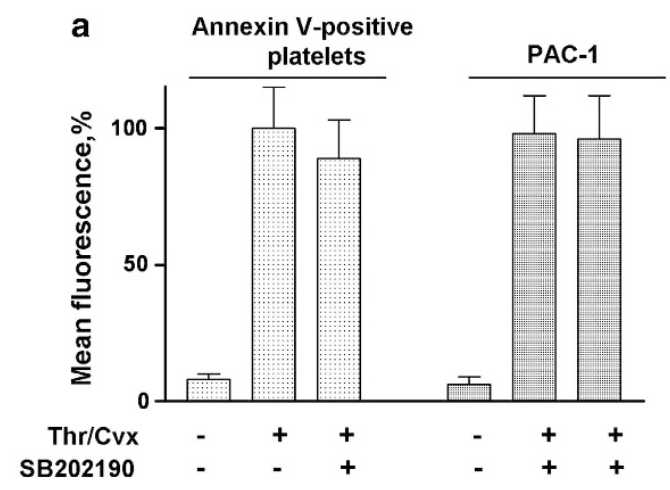

b

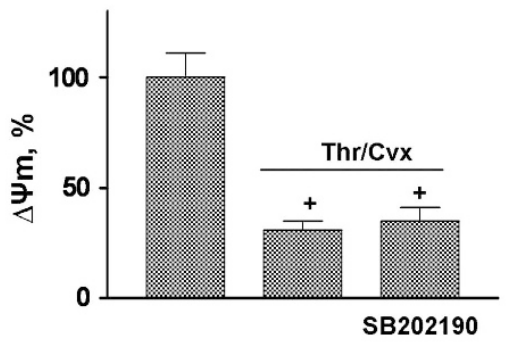

C

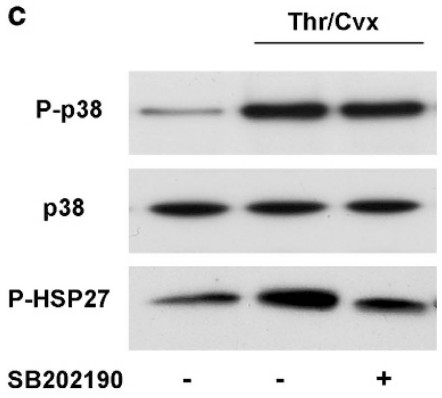

d

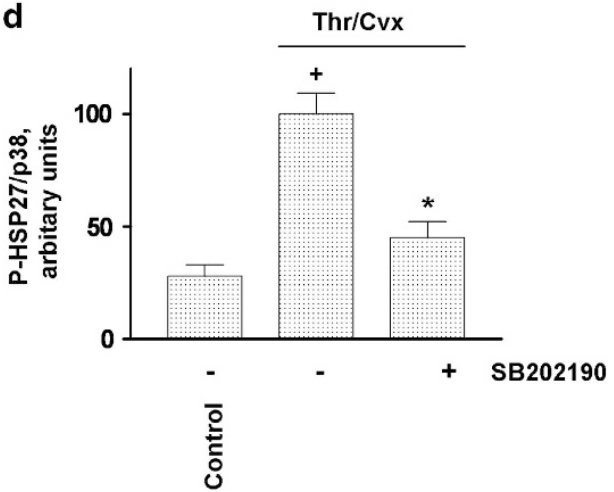

Figure 3 p38 inhibitor does not prevent PS surface exposure, decreased $\Delta \Psi_{\mathrm{m}}$, and integrin $\alpha$ llb $\beta 3$ activation in platelets stimulated with Thr/Cvx (a) FACS analysis of Annexin V-positive cells and PAC-1 binding and (b) $\Delta \Psi_{\mathrm{m}}$ in WP $\left(1 \times 10^{7} / \mathrm{ml}\right)$ stimulated by Thr $/ \mathrm{Cvx}$ or pretreated (10 min, $\left.1 \mu \mathrm{M}\right)$ with p38 inhibitor (SB202190). In (a) and (d), Thr/Cvx was taken as 100\%; in (b), control was taken as 100\%. Data are presented as means \pm S.E.M, $n=6 ;+P<0.05$ compared with the control, ${ }^{*} P<0.05$ compared with platelets incubated with Thr/Cvx. (c) Western blot and (d) densitometry analyses of p38 and HSP27 phosphorylation in WP $\left(3 \times 10^{8} / \mathrm{ml}\right)$ stimulated with Thr/Cvx or pretreated (10 min, $1 \mu \mathrm{M})$ with $\mathrm{p38}$ inhibitor (SB202190). The data shown are representative of three independent experiments

$\Delta \Psi_{\mathrm{m}}$ (Figure $\left.5 \mathrm{a}\right)$, and decreased the procaspase 3 cleavage (Figures $5 d$ and e) induced by ABT-737 and procaspase 3 cleavage in stored platelets after $24 \mathrm{~h}$ (Figure $5 \mathrm{c}$ ). At low concentrations, AA also decreased the Annexin $\mathrm{V}$ binding induced by Thr/Cvx and ABT-737. In accordance with these data, AA induced MP formation only at high concentrations (Figures 6a and b).

ROS generated by activated platelets are not directly correlated with apoptotic events. AA can be involved in the regulation of ROS production as a by-product during the oxidation of AA by cyclooxygenase or lipoxygenase. ${ }^{37}$ In addition, AA can directly activate NADPH oxidase, inducing ROS generation. ${ }^{46}$ As MP formation in platelets may be induced by ROS, ${ }^{47,48}$ we compared MP formation and ROS production in platelets activated by $\mathrm{ABT}-737(1 \mu \mathrm{M})$, AA $\left(10^{-6}\right.$ and $\left.10^{-4} \mathrm{M}\right)$, and Thr/Cvx $(5 \mathrm{mU} / 5 \mathrm{ng} / \mathrm{ml})$. AA at a concentration of $10^{-4} \mathrm{M}$ induced the highest amount of
MPs (2.7 \pm 0.34 fold compared with the control taken as 1$)$, and Thr/Cvx induced $1.7 \pm 0.2$; neither a low concentration of AA $\left(10^{-6} \mathrm{M}\right)$ nor $1 \mu \mathrm{M}$ ABT-737 induced significant MP formation (Figures $6 a$ and $b$ ).

ROS production was strongly induced by AA at a low but not at a high concentration ( $27 \pm 5.6$ and $3 \pm 1.5$-fold respectively, compared with the control taken as 1) (Figure 6c). Thr/Cvx stimulation also significantly increased ROS production (20 \pm 4 -fold, compared with the control taken as 1), whereas ABT-737 had no effect on platelet ROS production (Figure 6c).

\section{Discussion}

In nucleated cells, stress-activated p38 MAPK is involved in apoptosis, cytokine production, cytoskeleton reorganization, and transcriptional regulation. p38 MAPK also appears to play a role in the pathogenesis of heart ischemia, sepsis, arthritis, 

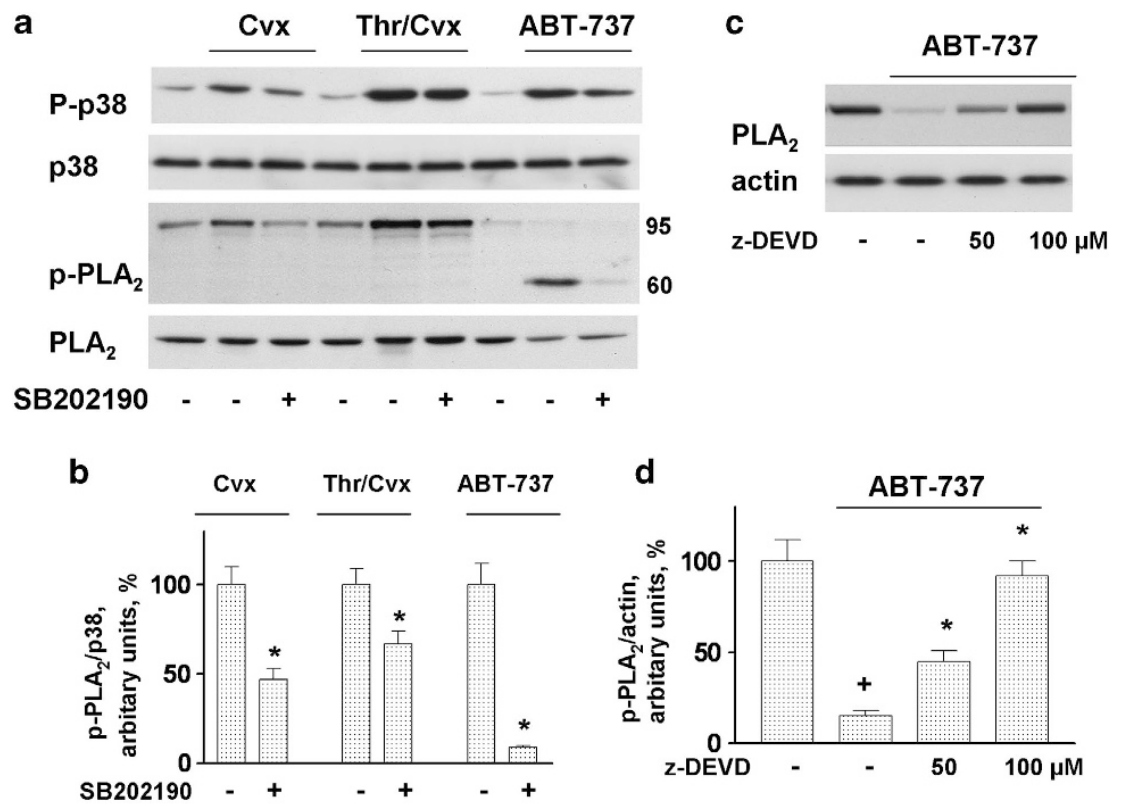

e

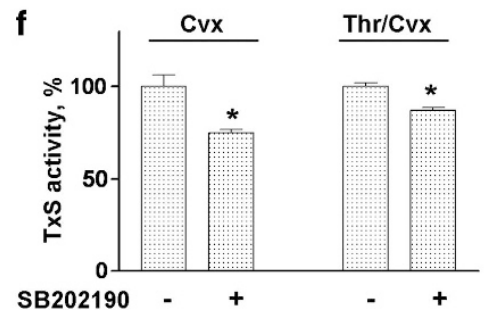

Figure 4 ABT-737 cleavage of platelet cPLA $A_{2}$ is caspase dependent. (a) Western blot and (b) densitometry analysis of p-cPLA in WP incubated with Cvx ( $5 \mathrm{ng} / \mathrm{ml}$ ), Thr/Cvx $(5 \mathrm{mU} / 5 \mathrm{ng} / \mathrm{ml})$, or ABT-737 $(1 \mu \mathrm{M})$ or pretreated $(10 \mathrm{~min}, 1 \mu \mathrm{M})$ with p38 inhibitor (SB202190). (c) Western blot and (d) densitometry analysis of cPLA $\mathrm{A}_{2}$ in WP after stimulation with ABT-737 or pretreated with the indicated concentrations of the caspase 3 inhibitor:z-DEVD. Western blot data are representative of three independent experiments of $\mathrm{p} 38$ and $\mathrm{CPLA}$ phosphorylation in WP $\left(4 \times 10^{8} / \mathrm{ml}\right)$. (e and f) ELISA data for the TxS activity in WP $\left(4 \times 10^{8} / \mathrm{ml}\right)$ activated by Cvx (5 ng/ml, $\left.5 \mathrm{~min}\right)$, Thr $/ \mathrm{Cvx}$ $(5 \mathrm{mU} / 5 \mathrm{ng} / \mathrm{ml}, 5 \mathrm{~min})$, or ABT-737 (1 $\mu \mathrm{M}, 30 \mathrm{~min})$ and after preincubation with $\mathrm{SB} 202190(1 \mu \mathrm{M}, 10 \mathrm{~min})$

human immunodeficiency virus infection, and Alzheimer's disease. $^{49}$ In platelets, p38 MAPK has been shown to be activated by almost all platelet agonists, including thrombin, collagen, $\mathrm{ADP}$, and $\mathrm{TxA}_{2} .{ }^{22-25}$ Nonetheless, the involvement of p38 in the mechanisms that trigger apoptosis in platelets has remained unclear. Therefore, we investigated the functions of $\mathrm{p} 38$ in the regulation of apoptosis induced by ABT-737 and the apoptosis-like events induced by strong agonists (Thr/ Cvx). We found that ABT-737 dose- and time-dependently resulted in the phosphorylation of p38 (Figure 1). The inhibition of p38 significantly prevented platelet apoptosis, as assessed by PS-positive cells, a decrease in mitochondrial potential, and cleavage of caspase 3 (Figure 2). cPLA $\mathrm{A}_{2}$ is an established p38 substrate in platelets, ${ }^{23,32-34}$ and we show that the ABT-737-induced activation of p38 triggered $\mathrm{CPLA} 2$ phosphorylation. In nucleated cells undergoing apoptosis, $\mathrm{CPLA}_{2}$ is cleaved and inactivated by caspase 3 activation. ${ }^{50,51}$ In platelets, $\mathrm{CPLA}_{2}$ was also cleaved upon $\mathrm{ABT}-737$ activation and inactivated by a caspase 3-dependent mechanism (Figures $4 \mathrm{a}$ and b). In contrast, Thr/Cvx treatment induced the phosphorylation of $\mathrm{CPLA}_{2}$ but did not promote its degradation (Figure 4a). Consistent with these data,
Thr/Cvx strongly enhanced $\mathrm{CPLA}_{2}$ activity compared with the effect of ABT-737 (Figure 4e). It is important to note that the inhibition of p38 significantly prevented the apoptosis induced by ABT-737 but had no effect on the apoptotic-like events triggered by Thr/Cvx stimulation (Figure 3). As ABT737-induced platelet apoptosis was directly correlated with the cleavage and inactivation of $\mathrm{CPLA}_{2}$ and because Thr/Cvx stimulation strongly activated $\mathrm{CPLA}_{2}$, which was responsible for AA generation, we tested whether $A A$ itself was involved in apoptosis. In nucleated cells, high concentrations of $A A$ contribute to mitochondrial dysfunction and apoptotic cell death, ${ }^{44,45,52}$ and AA also promotes apoptosis in stored platelets. $^{39}$ In addition, the concentration of AA can increase up to 10-fold during cerebral or heart ischemia compared with normal physiological conditions. ${ }^{53,54}$ Therefore, we tested the effects of different $A A$ concentrations on hallmarks of platelet apoptosis. AA at low concentrations $\left(10^{-7}-10^{-6} \mathrm{M}\right)$ enhanced $\Delta \Psi_{\mathrm{m}}$, but had no influence on PS externalization and did not cleave caspase 3 . In contrast, AA at high concentrations $\left(10^{-5}-10^{-4} \mathrm{M}\right)$ induced a decrease in $\Delta \Psi_{\mathrm{m}}$, enhanced PS externalization, and activated caspase 3 (Figure 5). Thus, the amount of AA might be an essential 

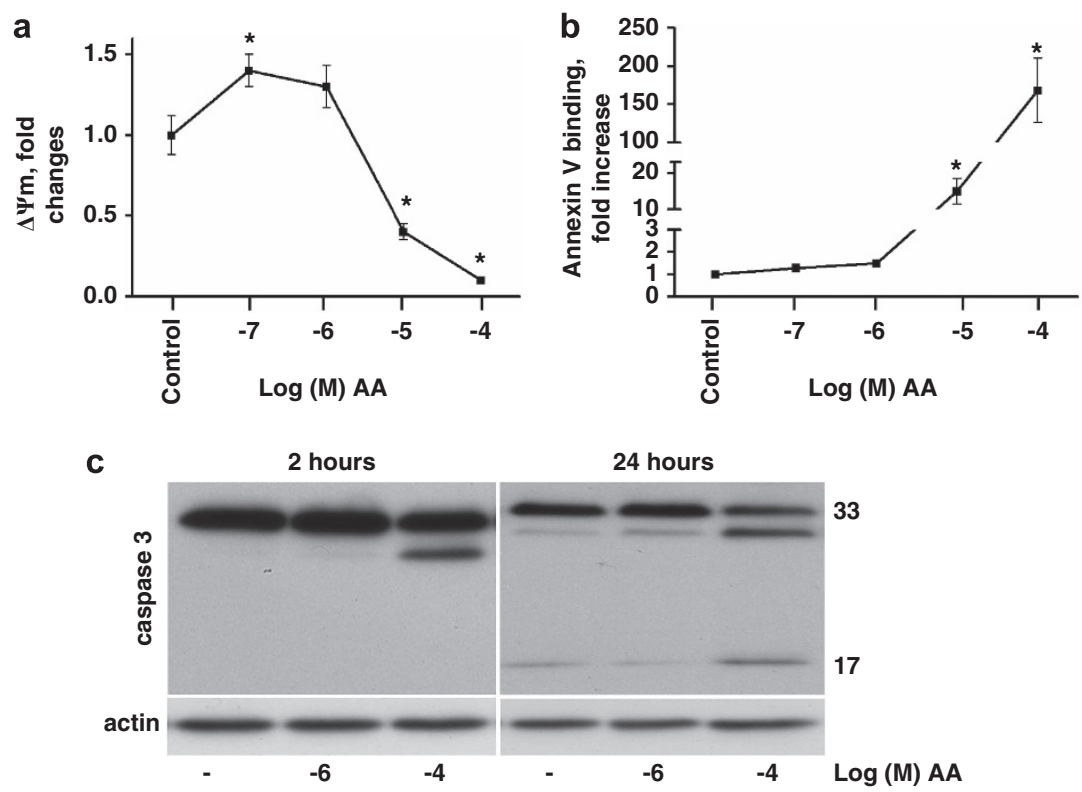

d
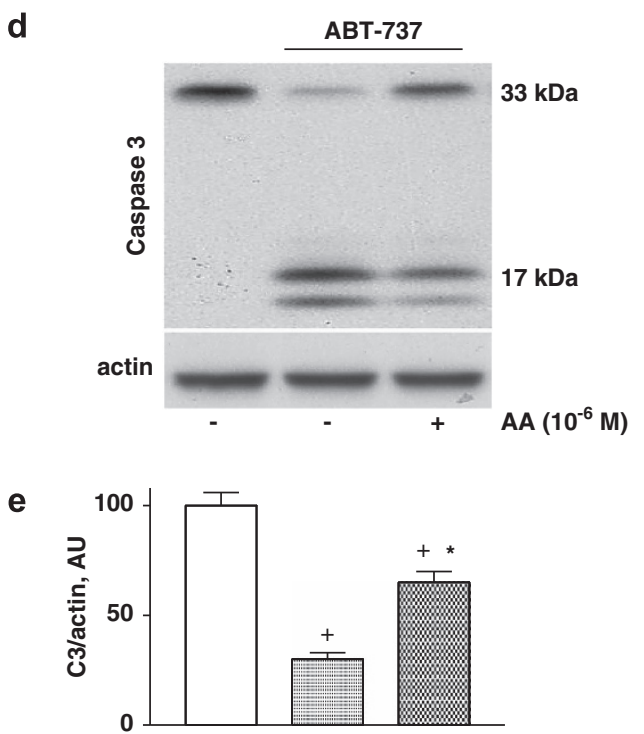

f

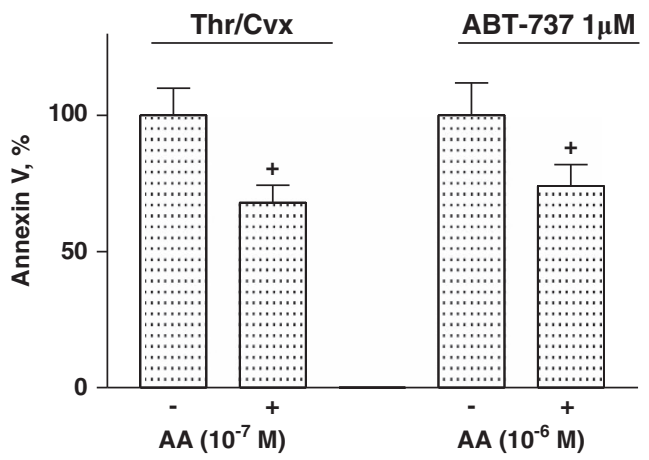

Figure 5 Arachidonic acid at low concentrations prevents, and at high concentrations induces apoptosis in platelets. (a) FACS analysis of $\Delta \Psi_{m}$ and (b) Annexin $V$ binding in WP $\left(1 \times 10^{7} / \mathrm{ml}\right)$ stimulated with AA for $5 \mathrm{~min}$ at the indicated concentrations. (f) Inhibition of Annexin V binding by AA $\left(10^{-7}-10^{-6} \mathrm{M}\right)$ in platelets stimulated with Thr/Cvx (5 min) and ABT-737 (1 $\mu \mathrm{M}, 30 \mathrm{~min})$. (c and d) Western blot analysis (data shown are representative of three independent experiments) of caspase 3 in WP $\left(4 \times 10^{8} / \mathrm{ml}\right)$ after stimulation with $A A$ at the indicated concentrations for 2 and $24 \mathrm{~h}(\mathbf{c})$ and after stimulation with ABT-737 alone and in combination with AA for 30 min (d) and (e) densitometry analysis of (d). In (e), the control was taken as $100 \%$. Data are presented as means \pm S.E.M, $n=6 ;+P<0.05$ compared with the control, ${ }^{*} P<0.05$ compared with platelets incubated with $\mathrm{ABT}-737$ 
factor for mediating pro or antiapoptotic-like effects in platelets. We next addressed whether different concentrations of $A A$ could prevent or enhance the apoptotic events induced by Thr/Cvx and ABT-737. Accordingly, we found that $\mathrm{AA}$ at low concentrations $\left(10^{-7}\right.$ for Thr/Cvx and $10^{-6}$ for ABT-737) inhibited the apoptotic events induced by both stimuli (Figure 5). The higher concentrations of AA required for the inhibitory effects of ABT-737-induced apoptosis were most likely associated with the inactivation of $\mathrm{CPLA}_{2}$ and consequently a reduced basal $\mathrm{AA}$ concentration in this case.

ROS are involved in cellular responses to stress ${ }^{55}$ and may contribute to various cellular pathological events, including apoptosis $^{56}$ and, in particular, MP formation. ${ }^{47,48}$ We investigated whether MP formation induced by ABT-737, Thr/Cvx, and $A A$ correlates with ROS production and found increases only in the Thr/Cvx- and $10^{-6} \mathrm{M}$ AA-treated platelets (Figure 6c), whereas MPs were enhanced only in the Thr/ Cvx- and $10^{-4} \mathrm{M} \mathrm{AA}$-stimulated platelets (Figures $6 a$ and $b$ ), indicating that ROS are most likely not directly linked to apoptotic events.

In summary, we show here that p38 MAP kinase plays a significant role in platelet apoptosis induced by ABT-737, but is not involved in the generation of the apoptotic-like events
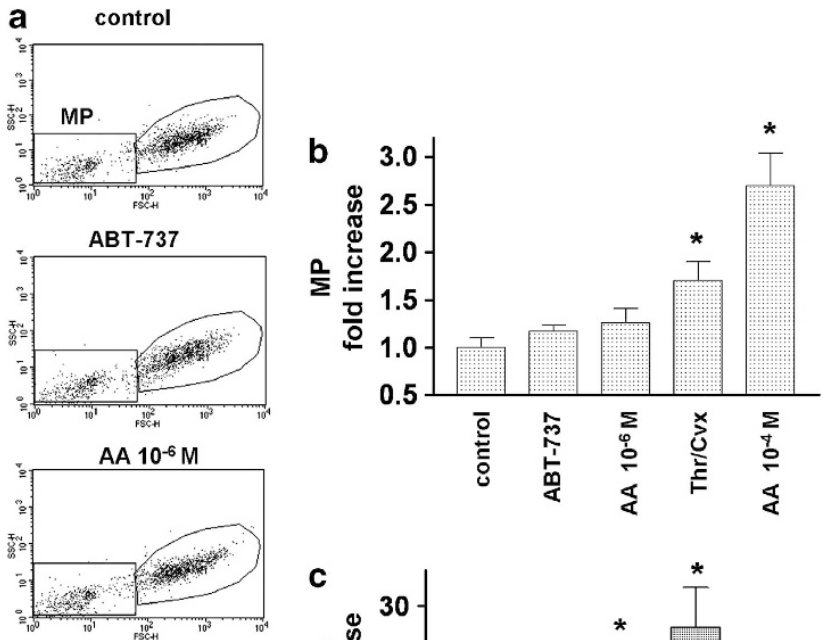

Thr/Cvx
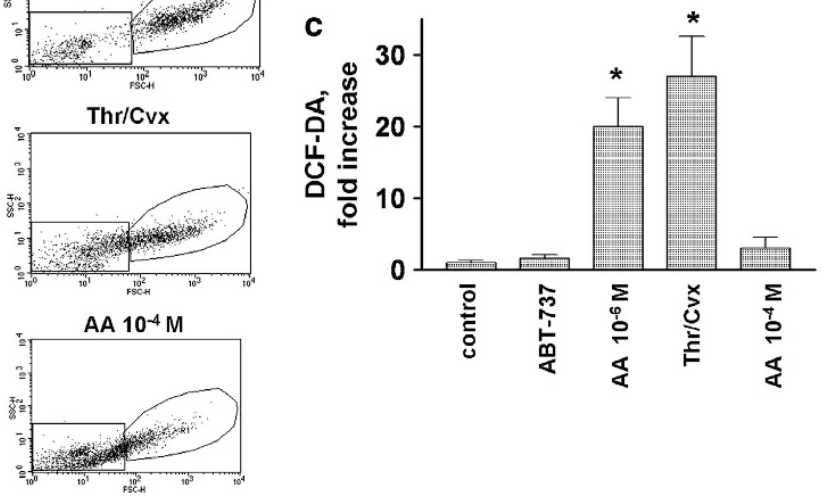

Figure 6 Microparticle generation and ROS production from platelets activated by different stimulators. Human WP were stimulated with ABT-737 (1 $\mu \mathrm{M}, 60 \mathrm{~min})$, $\mathrm{Thr} / \mathrm{Cvx}(5 \mathrm{mU} / 5 \mathrm{ng} / \mathrm{ml}, 2 \mathrm{~min})$, and AA at the indicated concentrations ( $5 \mathrm{~min})$ and processed for FACS analysis of MP formation, as assessed by the SSC/FSC plot ( $\mathbf{a}$ and $\mathbf{b}$ ) and (c) ROS production (DCF-DA fluorescence). The MP counts and DCF-DA fluorescence are presented as a fold increase compared with the control taken as 1. Data are presented as means \pm S.E.M, $n=4 ;{ }^{*} P<0.05$ compared with the control. (a) Representative plots (SSC/FSC) of the original data triggered by physiological stimuli (Thr/Cvx). Consistently, under physiological conditions, the p38-triggered activation of $\mathrm{CPLA}_{2}$, release of $A A$, and ROS generation may serve as mechanisms to protect cells from apoptosis. In contrast, a high concentration of AA (as often observed under pathological conditions) may promote proapoptotic events.

\section{Materials and Methods}

Materials. Thrombin was obtained from Roche (Mannheim, Germany), and convulxin (Cvx) (ligand of glycoprotein VI from the snake venom Crotalus durissus terrificus) was purchased from LOXO (Dossenheim, Germany). SB202190 and z-DEVD-fmk were purchased from Calbiochem (Schwalbach, Germany), and ABT737 was provided by Selleck Chemicals (Munich, Germany). Antibodies against p38, phospho-p38, and actin were obtained from Sigma (Munich, Germany). Antibodies against phospho-HSP27, phospho-cPLA, $\mathrm{CPLA}_{2}$, and caspase 3 were from Cell Signaling (Frankfurt, Germany). Anti-rabbit and anti-mouse IgG conjugated with horseradish peroxidase were obtained from Amersham, Pharmacia Biotech (Freiburg, Germany). The fluorescent dyes Annexin-V-PE and PAC-1 were obtained from BD-Bioscience (Heidelberg, Germany). JC1 was obtained from Invitrogen (Eugen, Germany), and $\mathrm{H}_{2}$ DCF-DA was purchased from Molecular Probes (Göttingen, Germany).

Platelet preparation. Human platelets were prepared and used as previously reported, ${ }^{57}$ with minor modifications. Blood was obtained from healthy volunteers according to our institutional guidelines and the Declaration of Helsinki. Our studies with human platelets were approved and recently (24 September, 2008) reconfirmed by the local ethics committee of the University of Würzburg (Studies Number 67/92 and 114/04).

Blood was collected into $1 / 7$ volume of ACD solution (12 mM citric acid, $15 \mathrm{mM}$ sodium citrate, $25 \mathrm{mM}$ D-glucose, and $2 \mu \mathrm{M}$ EGTA, final concentrations). Platelet rich plasma was obtained by a 5 -min centrifugation at $330 \times \mathrm{g}$. To reduce leukocyte contamination, Platelet rich plasma was diluted 1:1 with PBS and centrifuged at $240 \times \mathrm{g}$ for $10 \mathrm{~min}$. The supernatant was centrifuged for $10 \mathrm{~min}$ at $430 \times \mathrm{g}$, and the pelleted platelets were washed once in CGS buffer ( $120 \mathrm{mM}$ sodium chloride, $12.9 \mathrm{mM}$ trisodium citrate, and $30 \mathrm{mM} \mathrm{D}$-glucose, $\mathrm{pH} \mathrm{6.5)} \mathrm{and} \mathrm{resuspended} \mathrm{in}$ HEPES buffer ( $150 \mathrm{mM}$ sodium chloride, $5 \mathrm{mM}$ potassium chloride, $1 \mathrm{mM}$ magnesium chloride, $10 \mathrm{mM}$ D-glucose, and $10 \mathrm{mM}$ HEPES, pH 7.4) without stirring; $1 \mathrm{mM} \mathrm{CaCl}_{2}$ was added directly before platelet stimulation.

WP were used at a concentration of $3 \times 10^{8} / \mathrm{ml}$ for western blot analysis and TxS activity, and a concentration of $1 \times 10^{7} / \mathrm{ml}$ was used for flow cytometry analysis.

Flow cytometry (FACS) analysis. FACS analysis was performed using a Becton Dickinson FACS Calibur with CELLQuest software, version 3.1f (Becton Dickinson, Heidelberg, Germany). For the detection of surface PS or activated $\alpha$ llb $\beta 3$ integrins, WP $(50 \mu \mathrm{l})$ were labeled with Annexin V-PE or PAC-1-FITC (both 1:10 dilution) for $10 \mathrm{~min}$ at RT after agonist stimulation. The platelets were then diluted 10 times with Annexin V-binding solution ( $140 \mathrm{mM} \mathrm{NaCl}, 10 \mathrm{mM} H E P E S$, and $2.5 \mathrm{mM}$ $\mathrm{CaCl}_{2}$ ) for Annexin $\mathrm{V}$ or PBS for PAC-1 and immediately analyzed by flow cytometry.

Analysis of mitochondrial membrane potential. The $\Delta \Psi_{\mathrm{m}}$ in human platelets was analyzed with $\mathrm{JC} 1$ dye $(1.5 \mu \mathrm{M}$ final concentration). JC1 was incubated with WP $(50 \mu \mathrm{l})$ for $10 \mathrm{~min}$ at RT, and the samples were diluted $(1: 10)$ in PBS and analyzed by FACS. Green fluorescence (FL1) and red fluorescence (FL2) were measured in logarithmic scales using voltage settings of 710 and 588 , respectively. Compensation settings (FL1-\%FL2 and FL2-\%FL1) were performed using FITC and PE beads (BD-Bioscience). JC1 is sensitive to $\Delta \Psi_{\mathrm{m}}$, and the ratio of fluorescence in FL2 to FL1 corresponds to changes in $\Delta \Psi_{\mathrm{m}}$.

Measurement of ROS production. Intracellular ROS production was analyzed by $\mathrm{H}_{2} \mathrm{DCF}-\mathrm{DA}$, as described previously. ${ }^{58}$ Briefly, WP were preloaded with $10 \mu \mathrm{M} \mathrm{H} \mathrm{H}_{2}$ DCF-DA for $30 \mathrm{~min}$ at $37^{\circ} \mathrm{C}$ in HEPES buffer. $\mathrm{H}_{2} \mathrm{DCF}-\mathrm{DA}$ is a cellpermeable, nonfluorescent dye converted intracellularly to cell-impermeable $\mathrm{H}_{2} \mathrm{DCF}$ by intracellular esterases; the dye can then be oxidized by ROS to the fluorescent species (DCF) that is measured by flow cytometry. After incubation with agonists, the reaction was stopped by diluting the platelets in PBS for FACS analysis.

Measurement of thromboxane synthase activity. The TxS activity $\left(\mathrm{TxA}_{2}\right.$ synthase) was measured as described ${ }^{59}$ using a method based on 
malondialdehyde formation by $\mathrm{TxA}_{2}$ synthase. For the experiments, $0.2-\mathrm{ml}$ aliquots of WP $\left(3 \times 10^{8} / \mathrm{ml}\right)$ were incubated with the reagents at $37^{\circ} \mathrm{C}$ with gentle shaking; the reaction was stopped by the addition of $0.115 \mathrm{ml}$ of ice-cold trichloroacetic acid (20\% wt/vol). The samples were kept on ice for $10 \mathrm{~min}$ and then centrifuged for $10 \mathrm{~min}$ at 14000 r.p.m. Equal volumes of thiobarbituric acid $(0.53 \% \mathrm{wt} / \mathrm{vol})$ and supernatant were combined and incubated for $30 \mathrm{~min}$ at $70{ }^{\circ} \mathrm{C}$. The mixture was then incubated for $30 \mathrm{~min}$ at room temperature, and fluorescence was measured with a Wallac Victor2 1420 Multilabel counter (Perkin Elmer Wallac Life and Analytical Sciences, Boston, MA, USA) at excitation and emission wavelengths of $520 \mathrm{nM}$ and $550 \mathrm{nM}$, respectively. Standards were prepared from the stable malondialdehyde derivate tetraethoxypropane with thiobarbituric acid in the presence of trichloroacetic acid.

Western blot analysis. For western blot analysis, WP were added directly to sodium dodecyl sulfate (SDS) gel-loading buffer and analyzed by SDSpolyacrylamide gel electrophoresis (PAGE), as described. ${ }^{57}$ The separated proteins were transferred to a nitrocellulose membrane and incubated with the primary antibody overnight at $4{ }^{\circ} \mathrm{C}$. For visualization of the signal, goat anti-rabbit or anti-mouse IgG conjugated with horseradish peroxidase was used as a secondary antibody, followed by ECL detection (Amersham, Pharmacia Biotech).

Data analysis. All experiments were performed with at least $n=4$, and the combined data are expressed as means \pm S.E.M Differences between groups were analyzed by ANOVA, followed by Bonferronís test; Student's $t$-test was used when appropriate. A value of $P<0.05$ was considered statistically significant.

\section{Conflict of Interest}

The authors declare no conflict of interest.

Acknowledgements. This study was supported by the DFG (SFB688, TP A2) and BMBF (01E01003).

1. Versteeg $\mathrm{HH}$, Heemskerk JW, Levi M, Reitsma PH. New fundamentals in hemostasis Physiol Rev 2013; 93: 327-358.

2. Semple JW, Italiano JE Jr, Freedman J. Platelets and the immune continuum. Nat Rev Immunol 2011; 11: 264-274.

3. Projahn D, Koenen RR. Platelets: key players in vascular inflammation. J Leukoc Biol 2012; 92: 1167-1175.

4. Geddis AE. The regulation of proplatelet production. Haematologica 2009; 94: 756-759.

5. Li J, Xia Y, Bertino AM, Coburn JP, Kuter DJ. The mechanism of apoptosis in human platelets during storage. Transfusion 2000; 40: 1320-1329.

6. Zhang H, Nimmer PM, Tahir SK, Chen J, Fryer RM, Hahn KR et al. Bcl-2 family proteins are essential for platelet survival. Cell Death Differ 2007; 14: 943-951.

7. Kodama T, Takehara T, Hikita H, Shimizu S, Shigekawa M, Li W et al. BH3-only activator proteins Bid and Bim are dispensable for Bak/Bax-dependent thrombocyte apoptosis induced by $\mathrm{Bcl}-\mathrm{xL}$ deficiency: molecular requisites for the mitochondrial pathway to apoptosis in platelets. J Biol Chem 2011; 286: 13905-13913.

8. Burkhart JM, Vaudel M, Gambaryan S, Radau S, Walter U, Martens $L$ et al. The first comprehensive and quantitative analysis of human platelet protein composition allows the comparative analysis of structural and functional pathways. Blood 2012; 120: e73-e82.

9. Pereira J, Soto M, Palomo I, Ocqueteau M, Coetzee LM, Astudillo S et al. Platelet aging in vivo is associated with activation of apoptotic pathways: studies in a model of suppressed thrombopoiesis in dogs. Thromb Haemost 2002; 87: 905-909.

10. Rand ML, Wang H, Bang KW, Poon KS, Packham MA, Freedman J. Procoagulant surface exposure and apoptosis in rabbit platelets: association with shortened survival and steadystate senescence. J Thromb Haemost 2004; 2: 651-659.

11. Remenyi $G$, Szasz R, Friese $P$, Dale GL. Role of mitochondrial permeability transition pore in coated-platelet formation. Arterioscler Thromb Vasc Biol 2005; 25: 467-471.

12. Rukoyatkina N, Begonja AJ, Geiger J, Eigenthaler M, Walter U, Gambaryan S. Phosphatidylserine surface expression and integrin alpha llb beta 3 activity on thrombin/ convulxin stimulated platelets/particles of different sizes. $\mathrm{Br} J$ Haematol 2009; 144: 591-602.

13. Tonon G, Luo X, Greco NJ, Chen W, Shi Y, Jamieson GA. Weak platelet agonists and U46619 induce apoptosis-like events in platelets, in the absence of phosphatidylserine exposure. Thromb Res 2002; 107: 345-350.

14. Wolf BB, Goldstein JC, Stennicke HR, Beere H, Amarante-Mendes GP, Salvesen GS et al. Calpain functions in a caspase-independent manner to promote apoptosis-like events during platelet activation. Blood 1999; 94: 1683-1692.

15. Leytin V, Allen DJ, Mykhaylov S, Lyubimov E, Freedman J. Thrombin-triggered platelet apoptosis. J Thromb Haemost 2006; 4: 2656-2663.
16. Lin KH, Chang HC, Lu WJ, Jayakumar T, Chou HC, Fong TH et al. Comparison of the relative activities of inducing platelet apoptosis stimulated by various platelet-activating agents. Platelets 2009; 20: 575-581.

17. Winkler J, Rand ML, Schmugge M, Speer O. Omi/HtrA2 and XIAP are components of platelet apoptosis signalling. Thromb Haemost 2013; 109: 532-539.

18. Galluzzi L, Vitale I, Abrams JM, Alnemri ES, Baehrecke EH, Blagosklonny MV et al. Molecular definitions of cell death subroutines: recommendations of the Nomenclature Committee on Cell Death 2012. Cell Death Differ 2012; 19: 107-120.

19. Jackson SP, Schoenwaelder SM. Procoagulant platelets: are they necrotic? Blood 2010; 116: 2011-2018.

20. Leung R, Gwozdz AM, Wang H, Bang KW, Packham MA, Freedman J et al. Persistence of procoagulant surface expression on activated human platelets: involvement of apoptosis and aminophospholipid translocase activity. J Thromb Haemost 2007; 5: 560-570.

21. Lopez JJ, Salido GM, Gomez-Arteta E, Rosado JA, Pariente JA. Thrombin induces apoptotic events through the generation of reactive oxygen species in human platelets. J Thromb Haemost 2007; 5: 1283-1291.

22. Kramer RM, Roberts EF, Strifler BA, Johnstone EM. Thrombin induces activation of $p 38$ MAP kinase in human platelets. J Biol Chem 1995; 270: 27395-27398.

23. Kramer RM, Roberts EF, Um SL, Borsch-Haubold AG, Watson SP, Fisher MJ et al. p38 mitogen-activated protein kinase phosphorylates cytosolic phospholipase $A_{2}$ (CPLA2) in thrombin-stimulated platelets. Evidence that proline-directed phosphorylation is not required for mobilization of arachidonic acid by CPLA2. J Biol Chem 1996; 271: 27723-27729.

24. Saklatvala J, Rawlinson L, Waller RJ, Sarsfield S, Lee JC, Morton LF et al. Role for p38 mitogen-activated protein kinase in platelet aggregation caused by collagen or a thromboxane analogue. J Biol Chem 1996; 271: 6586-6589.

25. Adam F, Kauskot A, Rosa JP, Bryckaert M. Mitogen-activated protein kinases in hemostasis and thrombosis. J Thromb Haemost 2008; 6: 2007-2016.

26. Mazharian A, Roger S, Maurice P, Berrou E, Popoff MR, Hoylaerts MF et al. Differential Involvement of ERK2 and p38 in platelet adhesion to collagen. J Biol Chem 2005; 280: 26002-26010.

27. Canobbio I, Reineri S, Sinigaglia F, Balduini C, Torti M. A role for p38 MAP kinase in platelet activation by von Willebrand factor. Thromb Haemost 2004; 91: 102-110.

28. Begonja AJ, Geiger J, Rukoyatkina N, Rauchfuss S, Gambaryan S, Walter U. Thrombin stimulation of $\mathrm{p} 38 \mathrm{MAP}$ kinase in human platelets is mediated by ADP and thromboxane A2 and inhibited by cGMP/cGMP-dependent protein kinase. Blood 2007; 109: 616-618.

29. Borsch-Haubold AG, Pasquet S, Watson SP. Direct inhibition of cyclooxygenase-1 and -2 by the kinase inhibitors SB 203580 and PD 98059 . SB 203580 also inhibits thromboxane synthase. J Biol Chem 1998; 273: 28766-28772.

30. Kato H, Takai S, Matsushima-Nishiwaki R, Adachi S, Minamitani C, Otsuka T et al. HSP27 phosphorylation is correlated with ADP-induced platelet granule secretion. Arch Biochem Biophys 2008; 475: 80-86.

31. Kuliopulos A, Mohanlal R, Covic L. Effect of selective inhibition of the p38 MAP kinase pathway on platelet aggregation. Thromb Haemost 2004; 92: 1387-1393.

32. Lin LL, Wartmann M, Lin AY, Knopf JL, Seth A, Davis RJ. CPLA2 is phosphorylated and activated by MAP kinase. Cell 1993; 72: 269-278.

33. Borsch-Haubold AG, Kramer RM, Watson SP. Phosphorylation and activation of cytosolic phospholipase $A_{2}$ by $38-k D a$ mitogen-activated protein kinase in collagen-stimulated human platelets. Eur J Biochem 1997; 245: 751-759.

34. Waterman WH, Molski TF, Huang CK, Adams JL, Sha'afi RI. Tumour necrosis factor-alphainduced phosphorylation and activation of cytosolic phospholipase $\mathrm{A}_{2}$ are abrogated by an inhibitor of the p38 mitogen-activated protein kinase cascade in human neutrophils. Biochem J 1996; 319, Pt 1 17-20.

35. Lin LL, Lin AY, Knopf JL. Cytosolic phospholipase $A_{2}$ is coupled to hormonally regulated release of arachidonic acid. Proc Natl Acad Sci USA 1992; 89: 6147-6151.

36. Shmelzer Z, Haddad N, Admon E, Pessach I, Leto TL, Eitan-Hazan Z et al. Unique targeting of cytosolic phospholipase $A_{2}$ to plasma membranes mediated by the NADPH oxidase in phagocytes. J Cell Biol 2003; 162: 683-692.

37. Kukreja RC, Kontos HA, Hess ML, Ellis EF. PGH synthase and lipoxygenase generate superoxide in the presence of NADH or NADPH. Circ Res 1986; 59: 612-619.

38. Edderkaoui M, Hong $\mathrm{P}$, Vaquero EC, Lee JK, Fischer L, Friess $\mathrm{H}$ et al. Extracellular matrix stimulates reactive oxygen species production and increases pancreatic cancer cell survival through 5-lipoxygenase and NADPH oxidase. Am J Physiol Gastrointest Liver Physiol 2005; 289: G1137-G1147.

39. van der Wal DE, Gitz E, Du VX, Lo KS, Koekman CA, Versteeg S et al. Arachidonic acid depletion extends survival of cold-stored platelets by interfering with the (glycoprotein Ibalpha-14-3-3zeta) association. Haematologica 2012; 97: 1514-1522.

40. De Genaro P, Simon MV, Rotstein NP, Politi LE. Retinoic acid promotes apoptosis and differentiation in photoreceptors by activating the P38 MAP kinase pathway. Invest Ophthalmol Vis Sci 2013; 54: 3143-3156.

41. Mayr M, Hu Y, Hainaut $H, X u$ Q. Mechanical stress-induced DNA damage and racp38MAPK signal pathways mediate p53-dependent apoptosis in vascular smooth muscle cells. Faseb J 2002; 16: 1423-1425.

42. Shou Y, Li L, Prabhakaran K, Borowitz JL, Isom GE. p38 mitogen-activated protein kinase regulates Bax translocation in cyanide-induced apoptosis. Toxicol Sci 2003; 75: 99-107.

43. Tripathi T, Smith AD, Abdi M, Alizadeh $H$. Acanthamoeba-cytopathic protein induces apoptosis and proinflammatory cytokines in human corneal epithelial cells by $\mathrm{CPLA}_{2}$ alpha activation. Invest Ophthalmol Vis Sci 2012; 53: 7973-7982. 
44. Penzo D, Tagliapietra C, Colonna R, Petronilli V, Bernardi P. Effects of fatty acids on mitochondria: implications for cell death. Biochim Biophys Acta 2002; 1555: 160-165.

45. Scorrano L, Penzo D, Petronilli V, Pagano F, Bernardi P. Arachidonic acid causes cel death through the mitochondrial permeability transition. Implications for tumor necrosis factor-alpha aopototic signaling. J Biol Chem 2001; 276: 12035-12040.

46. Shiose $\mathrm{A}$, Sumimoto $\mathrm{H}$. Arachidonic acid and phosphorylation synergistically induce a conformational change of p47phox to activate the phagocyte NADPH oxidase. $J$ Biol Chem 2000; 275: 13793-13801.

47. Brill A, Chauhan AK, Canault M, Walsh MT, Bergmeier W, Wagner DD. Oxidative stress activates ADAM17/TACE and induces its target receptor shedding in platelets in a p38dependent fashion. Cardiovasc Res 2009; 84: 137-144.

48. Nardi MA, Gor Y, Feinmark SJ, Xu F, Karpatkin S. Platelet particle formation by ant GPIIla49-66 Ab, $\mathrm{Ca}_{2}{ }^{+}$ionophore A23187, and phorbol myristate acetate is induced by reactive oxygen species and inhibited by dexamethasone blockade of platele phospholipase A, 12-lipoxygenase, and NADPH oxidase. Blood 2007; 110: 1989-1996.

49. Obata T, Brown GE, Yaffe MB. MAP kinase pathways activated by stress: the p38 MAPK pathway. Crit Care Med 2000; 28: N67-N77.

50. Adam-Klages S, Schwandner R, Luschen S, Ussat S, Kreder D, Kronke M. Caspasemediated inhibition of human cytosolic phospholipase $A_{2}$ during apoptosis. J Immunol 1998; 161: 5687-5694

51. Atsumi G, Tajima M, Hadano A, Nakatani Y, Murakami M, Kudo I. Fas-induced arachidonic acid release is mediated by $\mathrm{Ca}_{2}{ }^{+}$-independent phospholipase $\mathrm{A}_{2}$ but not cytosolic phospholipase $A_{2}$, which undergoes proteolytic inactivation. J Biol Chem 1998; 273 13870-13877.

52. Kriem B, Sponne I, Fifre A, Malaplate-Armand C, Lozac'h-Pillot K, Koziel V et al. Cytosolic phospholipase $A_{2}$ mediates neuronal apoptosis induced by soluble oligomers of the amyloid-beta peptide. Faseb J 2005; 19: 85-87.
53. Prinzen FW, Van der Vusse GJ, Arts T, Roemen TH, Coumans WA, Reneman RS Accumulation of nonesterified fatty acids in ischemic canine myocardium. Am J Physiol 1984; 247: H264-H272.

54. Westerberg E, Deshpande JK, Wieloch T. Regional differences in arachidonic acid release in rat hippocampal CA1 and CA3 regions during cerebral ischemia. J Cereb Blood Flow Metab 1987; 7: 189-192.

55. Jiang F, Zhang Y, Dusting GJ. NADPH oxidase-mediated redox signaling: roles in cellular stress response, stress tolerance and tissue repair. Pharmacol Rev 2011; 63: 218-242.

56. Lambeth JD. NOX enzymes and the biology of reactive oxygen. Nat Rev Immunol 2004; 4: 181-189.

57. Gambaryan S, Geiger J, Schwarz UR, Butt E, Begonja A, Obergfell A et al. Potent inhibition of human platelets by cGMP analogs independent of cGMP-dependent protein kinase. Blood 2004; 103: 2593-2600.

58. Begonja AJ, Gambaryan S, Geiger J, Aktas B, Pozgajova M, Nieswandt B et al. Platelet $\mathrm{NAD}(\mathrm{P}) \mathrm{H}$-oxidase-generated ROS production regulates alphallbbeta3-integrin activation independent of the NO/cGMP pathway. Blood 2005; 106: 2757-2760.

59. Aktas B, Utz A, Hoenig-Liedl P, Walter U, Geiger J. Dipyridamole enhances NO/cGMPmediated vasodilator-stimulated phosphoprotein phosphorylation and signaling in human platelets: in vitro and in vivolex vivo studies. Stroke 2003; 34: 764-769.

cc) (1) $(-)$ Cell Death and Disease is an open-access journal Br no published by Nature Publishing Group. This work is licensed under a Creative Commons Attribution-NonCommercialNoDerivs 3.0 Unported License. To view a copy of this license, visit http://creativecommons.org/licenses/by-nc-nd/3.0/ 